\title{
Pengembangan Aplikasi Kinect Digital Display Pakaian Adat Indonesia
}

\author{
I Gede Mahendra Darmawiguna \\ Pendidikan Teknik Informatika \\ Universitas Pendidikan Ganesha \\ Singaraja-Bali, Indonesia \\ mahendra.darmawiguna@undiksha.ac.id
}

\author{
I Made Gede Sunarya \\ Pendidikan Teknik Informatika \\ Universitas Pendidikan Ganesha \\ Singaraja-Bali, Indonesia \\ sunarya@undiksha.ac.id
}

\author{
Ni Putu Ratna Puspitarini \\ Pendidikan Teknik Informatika \\ Universitas Pendidikan Ganesha \\ Singaraja-Bali, Indonesia \\ 1115051060@undiksha.ac.id
}

\begin{abstract}
Abstrak--- Pakaian adat tradisional merupakan simbol dari suatu daerah. Pakaian adat sangat identik dalam suatu prosesi upacara adat di Indonesia. Pakaian adat biasanya dipakai untuk memperingati hari besar seperti kelahiran, pernikahan, kematian, serta hari-hari besar keagamaan. Tujuan dari penelitian ini adalah: 1). Membuat rancang bangun pengembangan Aplikasi Kinect Digital Display Pakaian Adat Indonesia, 2). Mengimplementasikan rancangan Aplikasi Kinect Digital Display Pakaian Adat Indonesia, 3). Mengetahui respon pengguna terhadap Aplikasi Kinect Digital Display Pakaian Adat Indonesia.

Metode penelitian yang digunakan adalah penelitian dan pengembangan. Aplikasi Kinect Digital Display Pakaian Adat Indonesia ini dikembangkan dengan model waterfall. Aplikasi ini diimplementasikan dengan bahasa pemrograman $C \#$ dengan menggunakan editor UNITY 3D dan Kinect sebagai sensor gerak.

Hasil akhir dari project ini berupa aplikasi desktop yang memberikan informasi dan pengetahuan mengenai pakaian adat tradisional Indonesia. Aplikasi ini dapat menampilkan objek 3D yang mampu mengikuti gerakan pengguna dan informasi dari pakaian adat ke-34 provinsi di Indonesia. Hasil pengujian aplikasi memperlihatkan bahwa aplikasi mampu digunakan dengan lancar pada kondisi tertentu dan respon dari penguna aplikasi dikategorikan sangat positif dengan ratarata persentase $93,8 \%$. Aplikasi Kinect Digital Display Pakaian Adat Indonesia ini dapat dijadikan sebagai media informasi, hiburan, maupun pelajaran tentang Keragaman Pakaian Adat Tradisional Indonesia.
\end{abstract}

Kata Kunci : Digital Display, Pakaian adat Indonesia, Kinect

Abstract-Traditional clothes are symbol of regions. The traditional clothes are identical in every ceremonial process in Indonesia. People usually wear the traditional clothes to celebrate a big day such as birth, marriage, death, and the religious feasts. The purpose of this research is: 1). To create an application development design of kinect Digital Display Indonesian Traditional Clothes, 2). Implementing the application design of Kinect Digital Display Indonesian Traditional Clothes, 3). Knowing the user's response of Kinect Digital Display Indonesian Traditional Clothes.

This research is in the form of Research and Development using waterfall model as the method of developing application. This application is implemented with the C\# using UNITY $3 D$ editor, and Kinect as motion sensors.

The final result of this research is a desktop application that provides information and knowledge about the Indonesian traditional clothes. This application displays 3D objects which is able to follow user movements and also the information of the Indonesian traditional clothes of 34 provinces. The test results showed that the application can be used with the current application in certain condition and the user's response of this application can be categorized as very positive response with an average percentage about $93.8 \%$. Kinect Digital Display Indonesian Traditional Clothes Application can be used as a information media, entertainment, and learning media about the diversity of Indonesian Traditional Clothes as well..

Keywords - Digital Display, Pakaian adat Indonesia, Kinect

\section{PENDAHULUAN}

Indonesia merupakan negara kepulauan yang terdiri dari ribuan pulau terbentang dari Sabang sampai Merauke. Indonesia memiliki 13.466 pulau dengan provinsi yang tercatat menurut Kementerian Dalam Negeri sejumlah 34 provinsi[1]. Banyaknya jumlah provinsi yang dimiliki Indonesia tentunya menciptakan beragam kebudayaan dan kesenian di masing-masing daerah, seperti rumah adat, pakaian adat, senjata tradisional, tarian, dan lain sebagainya yang terkenal 
bahkan hingga mancanegara. Salah satu contoh kebudayaan khas Indonesia yaitu pakaian adat. Perbedaan pakaian adat setiap daerah dapat dilihat dari desain, motif, dan bahan yang digunakan. Warisan budaya yang sangat kaya ini patut dilestarikan oleh masyarakat Indonesia, agar nantinya kebudayaan ini tidak punah dan didominasi oleh kebudayaan luar. Beberapa upaya yang telah dilakukan oleh pemerintah maupun swasta untuk tetap melestarikan simbol simbol kebudayaan seperti rumah dan pakaian adat adalah dengan membangun museum-museum dan taman rekreasi cagar budaya.

Museum Bali merupakan salah satu museum yang berlokasi di Jl. Mayor Wisnu No.1, Denpasar, Bali. Museum ini menyajian penyimpanan peningggalan masa lampau manusia dan benda-benda etnografi seperti peralatan dan perlengkapan hidup, kesenian, keagamaan, bahasa tulisan dan lain-lainnya yang mencerminkan kehidupan dan perkembangan kebudayaan Bali. Namun berdasarkan data yang diperoleh dari Museum Bali, jumlah pengunjung dari tahun 2010 - 2013 berturut-turut mengalami penurunan yaitu 46.310, 35.055, 28.226 dan 25.501 orang[2]. Kenyataan yang terjadi saat ini menunjukkan bahwa museum sebagai sumber informasi kebudayaan dan kesejarahan kurang diminati oleh masyarakat. Salah satu alasan kurangnya minat pengunjung museum yaitu penyajian artefak yang cenderung monoton[3].

Upaya pelestarian dengan memanfaatkan perkembangan teknologi sangat dibutuhkan dalam hal membantu pemberian informasi dan edukasi kepada wisatawan maupun masyarakat utamanya generasi muda mengenai kebudayan Indonesia dalam hal ini rumah adat tradisional dan pakaian adat tradisional daerah di Indonesia. Memanfaatkan kecanggihan teknologi untuk melakukan promosi atau memperkenalkan budaya juga telah dikembangkan oleh Anantarupa Studio dan didukung oleh Kementerian Pendidikan dan Kebudayaan. Anantapura membuat aplikasi bernama Culture ARhibition yang merupakan sebuah aplikasi di perangkat mobile dan lembaran kartu yang mendukung teknologi realitas tertambah atau augmented reality (AR), pengetahuan tentang budaya Indonesia bisa dipelajari secara lebih interaktif. Culture ARhibition telah mendokumentasikan kebudayaan 12 provinsi yang ada di Indonesia, meliputi DKI Jakarta, Jawa Barat, dan seluruh provinsi di pulau Sumatera[4].

Berdasarkan pemaparan permasalahan di atas, peneliti termotivasi untuk merancang dan mengembangkan sebuah aplikasi Virtual Reality dikombinasikan dengan teknologi kinect yang akan diaplikasikan di Museum Bali. Aplikasi ini menampilkan objek 3D dari pakaian adat tradisional Indonesia yang dapat bergerak atraktif sesuai gerakan pengguna. Dengan aplikasi ini pengguna juga dapat langsung mengambil gambar atau foto pada saat objek 3D pakaian adat tradisional Indonesia yang sedang ditampilkan. Aplikasi ini juga memfasilitasi pengguna dengan fitur yang menyajikan informasi mengenai pakaian adat tradisional Indonesia berupa audio dengan 2 bahasa pilihan. Selain berfungsi untuk memperkenalkan pakaian adat tradisional Indonesia juga dapat digunakan sebagai sarana promosi Museum Bali sebagai media edukasi budaya serta upaya melestarikan dan mempromosikan kearifan lokal Indonesia dengan lebih menarik dan modern, dalam bentuk penelitian yang berjudul: "Pengembangan Aplikasi Kinect Digital Display Pakaian Adat Indonesia".

\section{KAJIAN TEORI}

\section{A. Pakaian Adat}

Pakaian adat merupakan simbol kebudayaan suatu daerah. Untuk menunjukkan nama daerah pakaian adat pun bisa dijadikan simbol tersebut. Pasalnya, setiap daerah di Indonesia memiliki pakaian adat yang berbeda-beda. Pakaian adat biasanya dipakai untuk memperingati hari besar seperti kelahiran, pernikahan, kematian, serta hari-hari besar keagamaan. Setiap daerah memiliki pengertian pakaian adat sendiri-sendiri. Sebagai simbol, pakain adat memang dijadikan penanda untuk sesuatu. Biasanya berupa doa atau mencerminkan suatu sikap[5].

Pemahaman nilai budaya yang dipesankan itu biasanya lahir melalui simbol-simbol dari berbagai macam hias pakaian adat Indonesia dari suatu masyarakat. Misalnya saja masyarakat suku Tolaki yang telah terhimpun dalam masyarakat kerajaan Konawe dan Mekongga, sudah tentu pakaian adat tradisional sejak saat itu mengandung fungsi religius di samping fungsi-fungsi lainnya. Dari arti simbolik yang dikandung oleh pakaian adat Indonesia tradisional sekaligus mengungkapkan bahwa warna, bentuk dan letak serta cara pemakaian pakaian adat Indonesia itu mengandung fungsi-fungsi etika, estetika, religius, sosial dan simbolis.

\section{B. Pengertian Computer Vision}

Computer Vision adalah proses otomatis yang mengintegrasikan seejumlah besar proses untuk persepsi visual, seperti akuisisi data, pengolahan citra, klasifikasi, pengenalan (recognition), dan membuat keputusan[6]. Computer Vision merupakan ilmu dan teknologi mesin yang melihat, di mana mesin mampu mengekstrak informasi dari gambar yang diperlukan untuk menyelesaikan tugas tertentu. Sebagai suatu disiplin ilmu, visi komputer berkaitan dengan teori di balik sistem buatan bahwa ekstrak informasi dari gambar. Data gambar dapat mengambil banyak bentuk, seperti urutan video, pandangan dari beberapa kamera, atau data multi-dimensi dari scanner medis. Sedangkan sebagai disiplin teknologi, computer vision berusaha 
untuk menerapkan teori dan model untuk pembangunan sistem computer vision.

Computer Vision didefinisikan sebagai salah satu cabang ilmu pengetahuan yang mempelajari bagaimana komputer dapat mengenali obyek yang diamati. Cabang ilmu ini bersama Artificial Intelligence akan mampu menghasilkan Visual Intelligence System. Perbedaannya adalah Computer Vision lebih mempelajari bagaimana komputer dapat mengenali obyek yang diamati. Namun komputer grafik lebih ke arah pemanipulasian gambar (visual) secara digital. Bentuk sederhana dari grafik komputer adalah grafik komputer 2D yang kemudian berkembang menjadi grafik komputer 3D, pemrosesan citra, dan pengenalan pola. Grafik komputer sering dikenal dengan istilah visualisasi data.

\section{Penerapan Computer Vision}

Dalam zaman yang semakin modern semakin banyak aplikasi dari computer vision yang dapat ditemui pada berbagai bidang, seperti:

- Industri : biasanya computer vision digunakan membantu proses otomasi industri, misalnya untuk quality control dimana computer vision berfungsi untuk melakukan pemeriksaan akhir terhadap produk untuk menemukan apakah ada cacat produksi. Dalam bidang industri terkadang disebut sebagai machine vision karena biasanya dihubungankan dengan perangkat lain.

- Robotika : digunakan untuk mengenali lingkungan sekitar, misalnya mobile robot, lengan robot yang dapat mengenali objek, drone robot (pesawat robot tanpa awak), robot humanoid, dan robot penjelajah.

- Otomotif : misalnya pada autonomus vehicle, fitur keselamatan rem otomatis untuk menghindari tabrakan dengan penyeberang jalan ataupun objek lain.

- Pendeteksi : misalnya alat presensi yang dapat mengenali wajah, alat pendeteksi tanda tangan, dan alat penghitung jumlah kendaraan yang melintasi jalan.

- Medis : biasanya digunakan untuk menangkap, mengolah, dan menganalisis gambar yang ditangkap dari pasien untuk mendiagnosis penyakit. Umumnya data gambar diambil dari mikroskop, $x$ ray, angiopraphy, ultrasonik, dan tomography. Aplikasi di bidang medis juga termasuk peningkatan kualitas gambar yang diinterpretasikan oleh manusia, misalnya gambar ultrasonik atau gambar $X$-ray, untuk mengurangi pengaruh noise.

\section{Kinect Xbox 360}

Kinect adalah alat penangkap gerakan yang dibuat oleh Microsoft untuk konsol game Xbox 360 dan Windows PC. Pada pertengahan tahun 2009, Microsoft mengumumkan dimulainya Proyek Natal (Natural User
Interface) yang nantinya dikenal sebagai kinect. Proyek ini mengembangkan position tracking yang ada pada Wii. Namun lain dengan Wii, kinect mengizinkan pemain untuk bergerak bebas berinteraksi dengan game. Di musim dingin 2010 penjualan kinect mencapai 10 juta unit dan tidak lama kemudian penjualannya melebihi pendahulunya. Kinect Xbox 360 merubah pandangan bagaimana cara bermain game karena dengan kinect tidak perlu adanya remote pengontrol.

Kinect bekerja dengan menyimpulkan posisi tubuh. Menyimpulkan posisi tubuh adalah proses dua tahap. Tahap pertama yaitu mengukur kedalaman peta dibangun dengan menganalisis speckle pattern sinar laser inframerah. Kinect menggunakan proyektor inframerah dan sensor, tidak menggunakan kamera $R G B$ untuk perhitungan kedalaman. Teknik menganalisis pola yang dikenal disebut cahaya terstruktur. Prinsip umum cahaya terstruktur adalah memproyeksikan pola yang dikenal ke scene dan menyimpulkan kedalaman dari deformasi pola tersebut.

Kinect menggunakan kamera dengan jenis $R G B 8$ bit dan $V G A$ beresolusi $640 \times 480$ pixel sedangkan kedalaman sensor monocrom atau hitam putih saja adalah 11 bit dan mengijinkan 2048 tingkatan sesitivitasnya. Video keluaran yang dihasilkannya bekerja di 30 frame per detik. Perangkat Kinect memiliki keterbatasan perkiraan kedalaman 0,7 - 6 meter. Bidang sudut pandang horizontal adalah $57^{\circ}$ dan vertikal $43^{\circ}$. Bidang pandang horizontal memiliki jarak minimum sekitar 0,8 meter dan 0,63 meter vertikal, sehingga Kinect memiliki resolusi perkiraan 1,3 milimeter per pixel[7].

Kinect menggabungkan cahaya terstruktur dengan dua teknik visi komputer klasik yaitu kedalaman dari fokus dan kedalaman dari stereo. Kedalaman dari fokus menggunakan prinsip bahwa hal-hal yang lebih kabur terlihat lebih jauh. Kedalaman dari stereo menggunakan paralaks. Jika seseorang melihat suatu scene dari sudut lain, benda yang dekat akan terlihat bergeser ke samping lebih dari benda yang berada pada tempat yang jauh. Kinect menganalisis pergeseran speckle pattern dengan memproyeksikan dari satu lokasi dan mengamati dari lokasi yang lain.

Tahap selanjutnya adalah menyimpulkan bagian tubuh menggunakan randomized decision forest. Menyimpulkan posisi tubuh adalah proses dua tahap. Pertama mengubah kedalaman image menjadi gambar bagian tubuh, dan kedua mengubah gambar bagian tubuh menjadi kerangka.

Ada beberapa alasan mengapa banyak orang senang menggunakan kinect, di antaranya:

a. Full Body Gaming. Kinect dapat merespon semua gerakan tubuh sehingga jika melakukan suatu gerakan seperti menendang maka kinect akan merespon gerakan tendangan tersebut. 
b. Recognition. Kinect dapat mengenali user dan mengakses avatar user sehingga user dapat mengakses game yang berbeda.

c. Voice Recognition. Kinect menggunakan teknologi yang dapat merespon suara sehingga user dapat mengontrol dengan menggunakan suara mereka tanpa menggunakan alat pengontrol.

d. Mudah digunakan oleh siapa saja, baik gamer ataupun bukan dapat bermain menggunakan kinect.

\section{E. Unity $3 D$}

Unity $3 D$ merupakan sebuah tools yang terintegrasi untuk membuat bentuk obyek 3 dimensi pada video games atau untuk konteks interaktif lain seperti Visualisasi Arsitektur atau animasi 3D real-time. Lingkungan dari pengembangan Unity 3D berjalan pada Microsoft Windows dan Mac Os $X$, serta aplikasi yang dibuat oleh Unity $3 D$ dapat berjalan pada Windows, Mac, Xbox 360, Playstation 3, Wii, iPad, iPhone dan tidak ketinggalan pada platform Android.

\section{F. Zigfu}

Berdasarkan pada web resmi dari Zigfu, Zigfu Development Kit adalah sebuah perangkat pengembangan yang mempermudah untuk pembuatan aplikasi berbasiskan motion control dengan kinect pada HTML5/Javascript, Unity $3 D$ dan Flash. Aplikasi yang dibuat dengan $Z D K$ bisa digunakan di semua sistem operasi, web browser, sensor 3D.

\section{G. Virtual Reality}

Virtual Reality terdiri dari dua kata yaitu virtual dan reality yang berarti maya dan realitas. Virtual reality adalah teknologi yang dapat berinteraksi dengan suatu lingkungan yang disimulasikan oleh komputer. Dalam teknisnya, virtual reality digunakan untuk menggambarkan lingkungan tiga dimensi yang dihasilkan oleh komputer dan dapat berinteraksi dengan seseorang. Virtual Reality $(V R)$ atau realitas maya adalah teknologi yang membuat pengguna dapat berinteraksi dengan suatu lingkungan yang disimulasikan oleh komputer (computer - simulated environment), suatu lingkungan sebenarnya yang ditiru atau benar-benar suatu lingkungan yang hanya ada dalam imaginasi[8].

\section{H. Blender}

Blender merupakan perangkat lunak untuk membuat animasi 3D. Blender memiliki fitur untuk membuat permainan. Blender tersedia untuk berbagai sistem operasi, seperti Microsoft Windows, Mac OS X, Linux, IRIX, Solaris, NetBSD, FeeBSD dan OpenBSD. Perangkat lunak ini berlisensi $G P L$, mempunyai kode sumber dan dapat diambil oleh siapa saja.

\section{METODOLOGI}

A. Analisis Masalah dan Solusi.

Pengembangan Aplikasi Kinect Digital Display Pakaian Adat Indonesia ini mengunakan proses SDLC (System Development Life Cycle). Model yang digunakan dalam membangun Aplikasi ini adalah Model Waterfall. Model Waterfall ini merupakan model klasik yang bersifat sistematis, berurutan dalam membangun perangkat lunak. Model ini adalah model yang muncul pertama kali yaitu sekitar tahun 1970 sehingga sering dianggap kuno, tetapi merupakan model yang paling banyak dipakai oleh para pengembang software. Pada model ini menyarankan pendekatan yang bersifat sistematis dan berurutan dalam membangun perangkat lunak, mulai dari tahap analisis, desain, implementasi, evaluasi.. Menurut Sommerville tahapan dalam model waterfall dapat dilihat seperti gambar berikut:

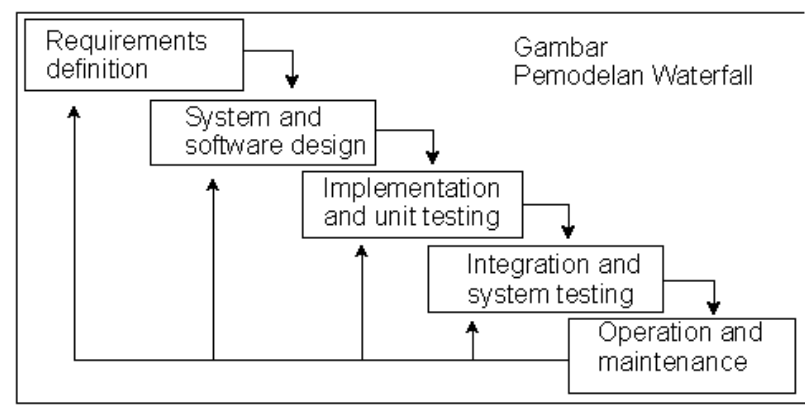

Gambar 1. Model Waterfall

Pada tahap analisis masalah, penulis mencari informasi terkait ketertarikan masyarakat untuk mengunjungi museum terutama Museum Bali. Berdasarkan hasil wawancara dengan Bapak Dewa Putu Ardana selaku pengurus Museum Bali, kepala bidang seksi edukasi dan preparasi juga menyatakan penggunaan teknologi dalam penyajian informasi terkait benda-benda koleksi museum akan memberikan nuansa baru di Museum Bali sehingga diharapkan dapat menarik minat pengunjung untuk datang ke museum.

Penulis tertarik untuk mengusulkan sebuah solusi yaitu dengan mengembangkan sebuah teknologi dalam bentuk Aplikasi Kinect Digital Display Pakaian Adat Indonesia. Aplikasi yang menggunakan teknologi Augmented Reality dikombinasikan dengan teknologi kinect akan menampilkan objek 3D dari pakaian adat tradisional Indonesia yang dapat bergerak atraktif sesuai gerakan pengguna. Aplikasi juga memfasilitasi pengguna dengan fitur yang menyajikan informasi mengenai pakaian adat tradisional Indonesia berupa audio dengan 2 bahasa pilihan. Selain berfungsi untuk memperkenalkan pakaian adat tradisional Indonesia juga dapat digunakan sebagai sarana promosi Museum Bali sebagai media edukasi budaya serta upaya 
melestarikan dan mempromosikan kearifan lokal Indonesia dengan lebih menarik dan modern.

Sehubungan dengan pemanfaatan teknologi Virtual Reality dalam aplikasi ini, penulis juge menggali informasi mengenai teknologi yang dibutuhkan dalam penelitian ini, seperti teknologi Unity 3D, Kinect Xbox 360, dan Zigfu. Dengan dikembangkannya Aplikasi Kinect Digital Display Pakaian Adat Indonesia ini diharapkan dapat memberikan daya tarik bagi masyarakat untuk berkunjung ke Museum Bali.

\section{B. Analisis Perangkat Lunak}

Tahap ini merupakan tahap kedua dalam model waterfall, yaitu masuk ke dalam bagian dari system and software design (sistem dan desain perangkat lunak). Dimana pada tahap ini akan dipaparkan mengenai tahapan awal dari perangkat lunak yang akan dikembangkan, yaitu meliputi kebutuhan perangkat lunak, tujuan pengembangan perangkat lunak, masukan dan keluaran perangkat lunak dan model fungsional perangkat lunak.

\section{Kebutuhan Perangkat Lunak}

Berdasarkan analisis terhadap Aplikasi Kinect Digital Display Pakaian Adat Indonesia ini, terdapat beberapa proses yang dapat diimplementasikan, yaitu:

\section{a. Kebutuhan Fungsional}

Aplikasi Kinect Digital Display Pakaian Adat Indonesia ini merupakan perangkat lunak yang diharapkan dapat memenuhi proses-proses sebagai berikut:

1) Aplikasi dapat menampilkan objek 3 dimensi dari pakaian adat tradisional ke 34 provinsi di Indonesia.

2) Aplikasi dapat menampilkan objek 3 dimensi Pakaian adat yang dapat mengikuti gerakan tubuh pengguna.

3) Aplikasi dapat menampilkan informasi sesuai dengan objek pakaian adat tradisional yang ditampilkan dengan 2 pilihan bahasa.

4) Aplikasi dapat mendokumentasikan gambar objek 3 dimensi dalam bentuk foto.

b. Kebutuhan Non Fungsional

Kebutuhan non fungsional dari aplikasi ini adalah sebagai berikut :

1) Pengembangan Aplikasi Kinect Digital Display Pakaian Adat Indonesia ini dibuat dengan user friendly agar lebih memudahkan pengguna dalam menggunakan aplikasi ini.

2) Pengembangan Aplikasi Kinect Digital Display Pakaian Adat Indonesia ini dapat dijalankan pada sistem operasi Windows XP ke atas.

\section{Tujuan Pengembangan Perangkat Lunak}

Aplikasi Kinect Digital Display Pakaian Adat Indonesia merupakan perangkat lunak yang digunakan untuk menampilkan objek 3D dari pakaian adat Tradisional Indonesia tepat ketika tubuh penguna dideteksi oleh sensor kinect. Aplikasi ini diharapkan mampu memenuhi proses-proses sebagai berikut:

a. Menampilkan antarmuka layar utama yang terdiri dari tombol next dan previous, tombol gender pria dan gender wanita, tombol capture, tombol zoom, serta tombol bahasa Indonesia dan bahasa Inggris.

b. Mampu mendeteksi tubuh pengguna dan menampilkan objek 3D dari pakaian adat Indonesia ke 34 provinsi.

c. Menampilkan onjek 3D pakaian adat tradisional Indonesia yang mampu mengikuti gerakan pengguna.

d. Menampilkan informasi dari masing-masing pakaian adat tradisional Indonesia dalam bentuk audio dengan pilihan bahasa Indonesia dan bahasa Inggris.

3. Masukan dan Keluaran Perangkat Lunak

Masukan dalam perangkat lunak Kinect Digital Display Pakaian Adat Indonesia adalah hasil tangkapan sensor kamera kinect ketika tulang dari pengguna dideteksi dan disesuaian dengan tulang pada objek 3D. Keluaran dari perangkat lunak ini adalah objek 3D dari pakaian adat tradisional Indonesia yang mampu mengikuti gerakan pengguna yang dihasilkan dari hasil pencocokan tulang pada pengguna dan tulang pada objek 3D, lengkap dengan narasi penjelasan dalam bahasa Indonesia dan bahasa Inggris.

\section{Model Fungsional Perangkat Lunak}

Pada model fungsional perangkat lunak menjelaskan gambaran umum dari perangkat lunak. Peneliti menggunakan UML (Unified Modeling Languange) dalam perancangan Pengembangan Aplikasi Kinect Digital Display Pakaian Adat Indonesia. UML adalah sebuah bahasa yang berdasarkan grafik atau gambar untuk memvisualisasi, menspesifikasikan, membangun, dan pendokumentasian dari sebuah pengembangan perangkat lunak berbasis OOP (Object-Oriented Programing). Pada tahapan ini peneliti telah merancang Use Case Diagram, Activity Aplikasi Kinect Digital Display Pakaian Adat Indonesia yang akan menjelaskan keseluruhan rancangan perangkat lunak yang akan dibuat.

\section{Perancangan Perangkat Lunak}

Tahap perancangan perangkat lunak adalah tahap selanjutnya setelah melakukan analisis perangkat lunak. Rancangan perangkat lunak yang dibuat bersifat user friendly agar pengguna merasa nyaman dan mudah untuk menggunakannya. Adapun bagian - bagian dari tahap ini dapat dipaparkan sebagai berikut. Pada 
perancangan perangkat lunak Kinect Digital Display Pakaian Adat Indonesia ini terdapat 2 tahapan yang dilalui, yaitu batasan perancangan perangkat lunak, dan perancangan antarmuka perangkat lunak.

1. Batasan Perancangan Perangkat Lunak

Adapun batasan perancangan perangkat lunak Aplikasi Kinect Digital Display Pakaian Adat Indonesia sebagai bentuk pelestarian pengenalan dan pelestarian kearifan lokal Indonesia dapat dipaparkan sebagai berikut.

a. Aplikasi yang dikembangkan akan menampilkan pakaian adat tradisional dari ke 34 provinsi di Indonesia dalam bentuk objek 3D,

b. Aplikasi ini hanya bisa digunakan dengan posisi tubuh menghadap lurus ke depan, agar tubuh pengguna dapat dideteksi dengan mudah oleh sensor kinect,

c. Aplikasi ini dikembangkan sesuai dengan teknologi windows batas terbawah yaitu Windows $X P$.

2. Perancangan Arsitektur Perangkat Lunak

Perancangan arsitektur perangkat lunak menggambarkan bagian-bagian modul, struktur ketergantungan antar modul, dan hubungan antara modul dari perangkat lunak yang dibangun.

a. Use Case Diagram

Use Case Diagram menggambarkan fungsionalitas yang diharapkan dari sebuah sistem. Menggambarkan kebutuhan sistem dari sudut pandang user, memfokuskan pada proses komputerisasi (automated process). Sebuah use case merepresentasikan sebuah interaksi antara aktor dengan system, terlihat pada Gambar 2.

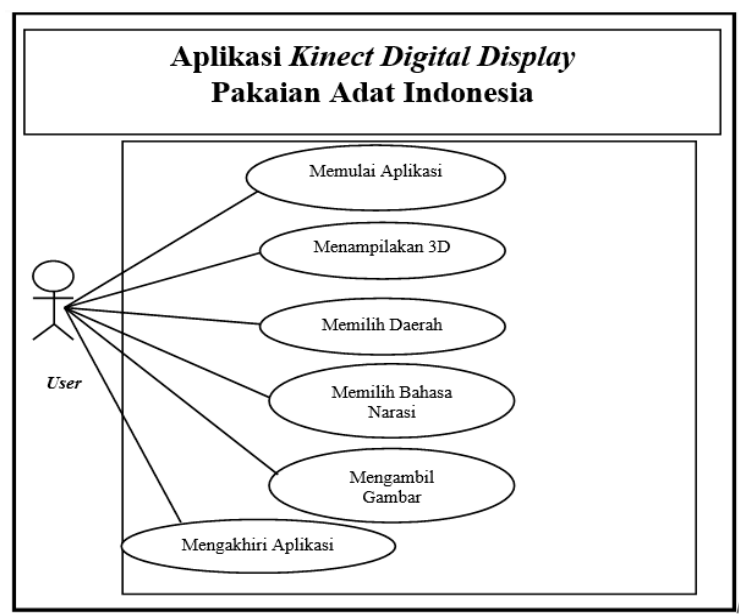

Gambar 2. Use Case Diagram Perangkat Lunak.

b. Tabel Skenario Perangkat Lunak

Berdasarkan Use Case Diagram tersebut, maka dapat ditentukan table scenario perangkat lunak dari Aplikasi Kinect Digital Display Pakaian Adat Indonesia seperti terlihat pada Table 1.
Tabel 1. Tabel Skenario Perangkat Lunak

\begin{tabular}{|c|c|}
\hline Tahap & Penjelasan \\
\hline 1. & User memulai aplikasi. \\
\hline 2. & $\begin{array}{l}\text { Kemudian aplikasi akan langsung menuju } \\
\text { tampilan awal (splash image) yang bersikan } \\
\text { logo Undiksha, logo LCI dan judul aplikasi. }\end{array}$ \\
\hline 3. & $\begin{array}{l}\text { Aplikasi akan menuju ke splash image yang } \\
2 \text { yang berisikan gambar petunjuk pose } \\
\text { penggunaan aplikasi. }\end{array}$ \\
\hline 4. & $\begin{array}{l}\text { Selanjutnya aplikasi akan langsung menuju } \\
\text { tampilan utama Display Pakaian Adat } \\
\text { Indonesia. Pada tampilan utama aplikasi } \\
\text { terdapat beberapa tombol yang dapat dipilih } \\
\text { user, diantaranya pilihan tombol bahasa } \\
\text { narasi (Indonesia dan Inggris), tombol jenis } \\
\text { kelamin (pria dan wanita), tombol previous } \\
\text { dan next, capture, dan zoom. }\end{array}$ \\
\hline 5. & $\begin{array}{l}\text { Aplikasi akan menampilkan pakaian adat } \\
\text { wanita Nangroe Aceh Darussalam sebagai } \\
\text { objek 3D default. Ketika user berpose di } \\
\text { depan kamera Kinect maka objek 3D } \\
\text { pakaian adat akan mengikuti gerakan user. }\end{array}$ \\
\hline 6. & $\begin{array}{l}\text { User memilih tombol jenis kelamin, apabila } \\
\text { menekan tombol jenis kelamin pria maka } \\
\text { objek 3D pakaian adat tradisional pria yang } \\
\text { akan ditampilkan di layar utama. Apabila } \\
\text { menekan tombol jenis kelamin wanita maka } \\
\text { objek 3D pakaian adat tradisional wanita } \\
\text { yang akan ditampilkan di layar utama }\end{array}$ \\
\hline 7. & $\begin{array}{l}\text { User memilih tombol bahasa narasi. Jika } \\
\text { tombol Indonesia yang ditekan maka } \\
\text { informasi pakaian adat akan ditampilkan } \\
\text { berupa audio dalam bahasa Indonesia. Dan } \\
\text { jika user menekan tombol Inggris maka } \\
\text { narasi yang ditampilkan adalah narasi } \\
\text { berbahasa Inggris. }\end{array}$ \\
\hline 8. & $\begin{array}{l}\text { User menekan tombol previous atau next } \\
\text { untuk mengganti pakaian daerah yang ingin } \\
\text { ditampilkan. }\end{array}$ \\
\hline 9. & $\begin{array}{l}\text { Saat User menekan tombol zoom, maka } \\
\text { akan muncul sub tombol zoom lainnya. } \\
\text { Diantaranya zoom atas, zoom bawah, zoom } \\
\text { lebar, zoom kurus, zoom pendek dan zoom } \\
\text { tinggi yang dapat digunakan utntuk } \\
\text { mengatur ukuran dari pakaian adat yang } \\
\text { ditampilkan. }\end{array}$ \\
\hline 10. & $\begin{array}{l}\text { Saat user menekan capture, maka aplikasi } \\
\text { akan mendokumentasikan tangkapan kamera } \\
\text { berupa foto. }\end{array}$ \\
\hline 11. & User mengakhiri aplikasi. \\
\hline
\end{tabular}


c. Activity Diagram

Activity

diagram menggambarkan berbagai alir aktivitas dalam sistem yang sedang dirancang, bagaimana masing-masing alur berawal, decision yang mungkin terjadi, dan bagaimana mereka berakhir. Berdasarkan use case diagram maka dapat ditentukan activity diagram dari Aplikasi Kinect Digital Display Pakaian Adat Indonesia, untuk activity diagram memulai aplikasi dapat dilihat pada Gambar 3. Activity diagram menampilkan objek 3D dapat dilihat pada Gambar 4. Activity diagram memilih daerah dapat dilihat pada Gambar 5. Activity diagram memilih narasi dapat dilihat pada Gambar 6. Activity diagram mengambil gambar dapat dilihat pada Gambar 7, dan activity diagram mengakhiri aplikasi dapat dilihat pada Gambar 8 .

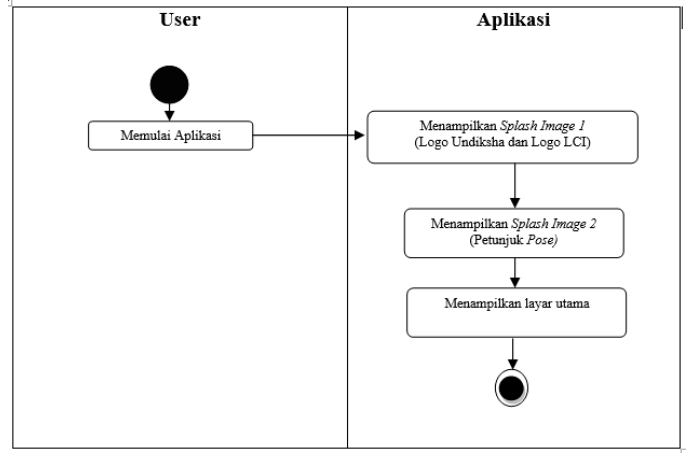

Gambar 3. Activity Diagram Memulai Aplikasi

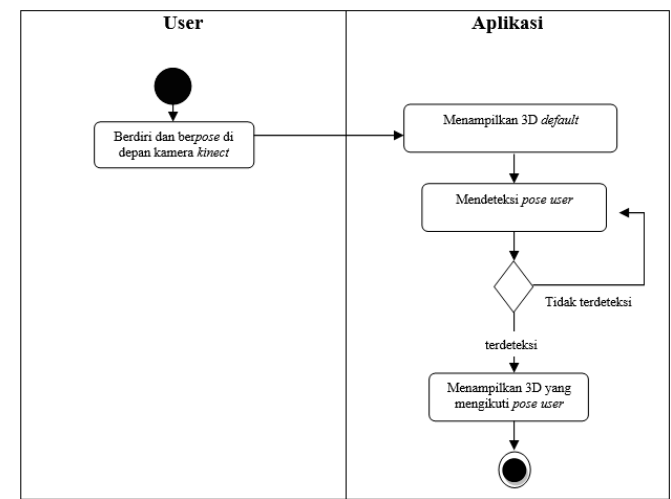

Gambar 4. Activity Diagram Menampilkan 3D

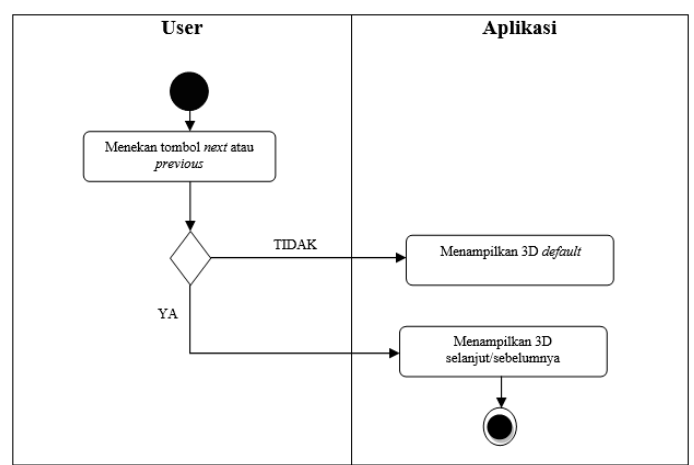

Gambar 5. Activity Diagram Memilih Daerah

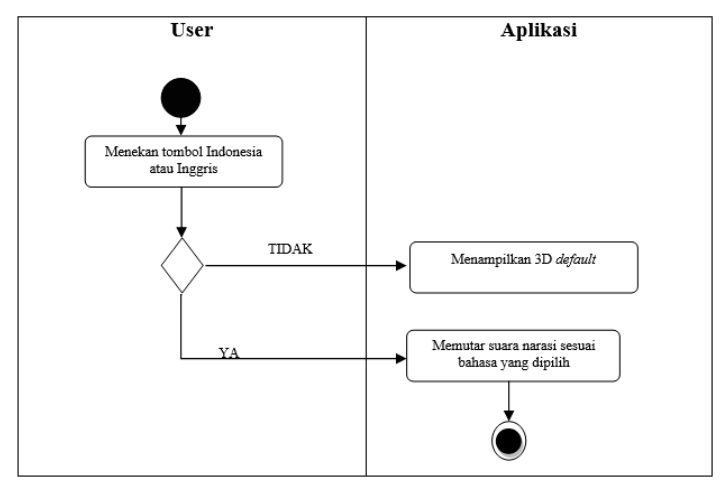

Gambar 6. Activity Diagram Memilih Bahasa Narasi

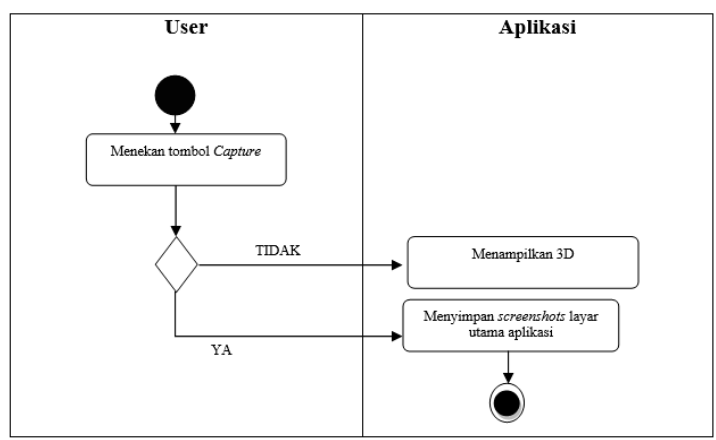

Gambar 7. Activity Diagram Mengambil Gambar

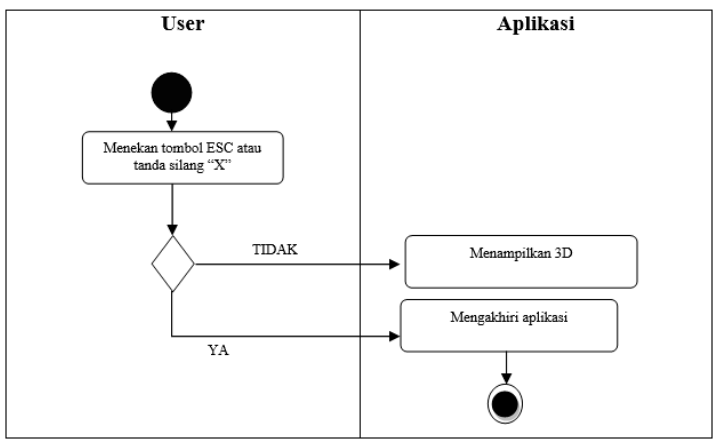

Gambar 8. Activity Diagram Mengakhiri Aplikasi

\section{PEMBAHASAN}

A. Implementasi Perangkat Lunak

Implementasi Aplikasi Kinect Digital Display Pakaian Adat Indonesia terdiri dari lingkungan implementasi perangkat lunak, batasan implementasi perangkat lunak, implementasi arsitektur perangkat lunak, serta implementasi layar antarmuka perangkat lunak Aplikasi Kinect Digital Display Pakaian Adat Indonesia. 
p-ISSN 2089-8673 | e-ISSN 2548-4265

Jurnal Nasional Pendidikan Teknik Informatika (JANAPATI)

Volume 6, Nomor 1, Maret 2017

1. Lingkungan Pengembangan Perangkat Lunak

Pada lingkungan perangkat lunak, Aplikasi

Kinect Digital Display Pakaian Adat Indonesia dijalankan pada lingkungan Sistem Operasi Microsoft Windows 8, UNITY, Zigfu, BLENDER, Adobe Photoshop CS5.

Pada lingkungan perangkat keras, Aplikasi Kinect Digital Display Pakaian Adat Indonesia dijalankan pada sebuah laptop dengan spesifikasi sebagai berikut: monitor 14 inchi dengan resolusi 1366 x 768, memori 4 GB RAM dan harddisk 500 GB, processor Intel ${ }^{\circledR}$ Core $^{\mathrm{TM}}$ i5 $1.70 \mathrm{Ghz}$, serta sebuah Kinect Xbox 360.

2. Batasan Implementasi Perangkat Lunak

Adapun batasan lingkungan implementasi Aplikasi Kinect Digital Display Pakaian Adat Indonesia dibatasi oleh hal berikut.

a. Spesifikasi perangkat minimal yang diperlukan untuk menjalankan aplikasi adalah sebagai berikut.
1) Processor Intel Dualcore
2) $R A M 1 G B$
3) Windows $X P S P 2$
4) GPU Intel HD

b. Aplikasi Kinect Digital Display Pakaian Ada Indonesia hanya menyimpan informasi pakaian adat Indonesia dari 34 propinsi .

c. Aplikasi hanya menampilkan informasi dalam bentuk visual berupa model 3D dari Pakaian Adat Indonesia dan audio berupa suara setiap Pakaian Adat Indonesia serta suara keterangan mengenai Pakaian Adat Indonesia dalam bahasa Indonesia dan Inggris. Selain itu aplikasi juga dapat mendokumentasikan tampilan layar aplikasi Pakaian Adat Indonesia.

d. Data informasi terkait obyek yang digunakan bersifat statis, dimana data secara langsung disimpan kedalam aplikasi tanpa menggunakan database.

e. Pengembangan aplikasi ini difokuskan dapat berjalan pada sistem operasi Windows.

3. Implementasi Arsitektur Perangkat Lunak

Sesuai dengan hasil perancangan arsitektur perangkat lunak, dapat diimplementasikan proses yang digunakan untuk membuat Aplikasi Kinect Digital Display Pakaian Adat Indonesia, yakni Zig.cs, ZigDepthViewer.cs, ZigEngageSingleUser.cs, ZigImageViewer.cs, Splash.cs, Tom.cs, Pose.cs, Zoom.cs, ExitOnEscape.cs, ZigSkeleton.cs. Penerapan pada perangkat lunak Unity menggunakan class - class yang disimpan dalam format file $C \#$. Implementasi arsitektur perangkat lunak Kinect Digital Display Pakaian Adat Indonesia dapat dilihat pada Tabel 2.
Tabel 2. Pemetaan Class Implementasi Arsitektur Perangkat Lunak

\begin{tabular}{|c|c|c|}
\hline $\begin{array}{c}\text { Bagan } \\
\text { Perancangan } \\
\text { Arsitektur } \\
\end{array}$ & $\begin{array}{l}\text { Implementas } \\
\text { i Proses }\end{array}$ & $\begin{array}{c}\text { Penjelasan } \\
\text { Implementasi Proses }\end{array}$ \\
\hline \multirow{6}{*}{$\begin{array}{l}\text { Main Camera } \\
\text { yang } \\
\text { mengatur } \\
\text { konten yang } \\
\text { ditampilkan } \\
\text { di layar } \\
\text { utama } \\
\text { Aplikasi }\end{array}$} & Splash.cs & $\begin{array}{l}\text { Class yang digunakan } \\
\text { untuk menampilkan } \\
\text { tampilan splash image } \\
\text { yang menampilkan } \\
\text { Logo Undiksha dan } \\
\text { LCI beserta nama } \\
\text { aplikasi }\end{array}$ \\
\hline & Zoom.cs & $\begin{array}{l}\text { Class yang digunakan } \\
\text { untuk menampilkan } \\
\text { pilihan jenis fitur zoom } \\
\text { pada aplikasi }\end{array}$ \\
\hline & Pose.cs & $\begin{array}{l}\text { Class yang digunakan } \\
\text { untuk menampilkan } \\
\text { tampilan splash image } \\
\text { yang menampilkan } \\
\text { petunjuk pose } \\
\text { penggunaan aplikasi }\end{array}$ \\
\hline & Tom.cs & $\begin{array}{l}\text { Class yang digunakan } \\
\text { untuk membuat tombol } \\
\text { yang akan ditampilkan } \\
\text { dilayar utama, serta } \\
\text { fungsi-fungsinya. }\end{array}$ \\
\hline & $\begin{array}{l}\text { ZigbuttonCa } \\
\text { pture }\end{array}$ & $\begin{array}{l}\text { Class yang digunakan } \\
\text { membuat tombol } \\
\text { capture beserta } \\
\text { fungsinya. }\end{array}$ \\
\hline & $\begin{array}{l}\text { ExitOnEsca } \\
\text { pe.cs }\end{array}$ & $\begin{array}{l}\text { Class ini digunakan } \\
\text { untuk menutup aplikasi } \\
\text { ketika pengguna } \\
\text { menekan tombo Escape } \\
\text { pada Keyboard. }\end{array}$ \\
\hline $\begin{array}{l}\text { Image untuk } \\
\text { menampilkan } \\
\text { Background }\end{array}$ & $\begin{array}{l}\text { ZigImageVie } \\
\text { wer.cs }\end{array}$ & $\begin{array}{l}\text { Class yang digunakan } \\
\text { untuk menampilkan } \\
\text { hasil tangkapan kamera } \\
\text { pada sebuah plane }\end{array}$ \\
\hline \multirow{3}{*}{$\begin{array}{l}\text { Zigfu untuk } \\
\text { mengenal dan } \\
\text { memproses } \\
\text { hasil } \\
\text { tangkapan } \\
\text { kamera kinect }\end{array}$} & Zig.cs & $\begin{array}{l}\text { Merupakan class yang } \\
\text { digunakan untuk } \\
\text { memproses dan } \\
\text { mengolah hasil } \\
\text { tangkapan kamera } \\
\text { kinect }\end{array}$ \\
\hline & $\begin{array}{l}\text { ZigDepthVie } \\
\text { wer.cs }\end{array}$ & $\begin{array}{l}\text { Merupakan class yang } \\
\text { digunakan untuk } \\
\text { mendeteksi dan } \\
\text { mengukur jarak antar } \\
\text { pengguna dengan } \\
\text { kamera kinect }\end{array}$ \\
\hline & $\begin{array}{l}\text { ZigEngageSi } \\
\text { ngleUser }\end{array}$ & $\begin{array}{l}\text { Merupakan class yang } \\
\text { digunakan untuk } \\
\text { menggerakan objek 3D } \\
\text { sesuai dengan hasil }\end{array}$ \\
\hline
\end{tabular}




\begin{tabular}{|c|c|c|}
\hline $\begin{array}{c}\text { Bagan } \\
\text { Arancangan } \\
\text { Arsitektur }\end{array}$ & $\begin{array}{c}\text { Implementas } \\
\text { i Proses }\end{array}$ & $\begin{array}{c}\text { Penjelasan } \\
\text { Implementasi Proses }\end{array}$ \\
\hline & & $\begin{array}{l}\text { tangkapan kamera pada } \\
\text { seorang pengguna }\end{array}$ \\
\hline
\end{tabular}

4. Implementasi Antarmuka Tampilan Aplikasi

Rancangan layar antarmuka perangkat lunak

Kinect Digital Display Pakaian Adat Indonesia diimplementasikan menggunakan fitur-fitur yang terdapat pada Unity $3 D$.

a. Implementasi Antarmuka Tampilan Layar Intro/Splash Image

Tampilan awal (splash image) akan tampil di layar ketika aplikasi mulai dijalankan, dimana akan ditampilkan logo UNDIKSHA dan LCI beserta nama aplikasi, dapat dilihat pada Gambar 9.
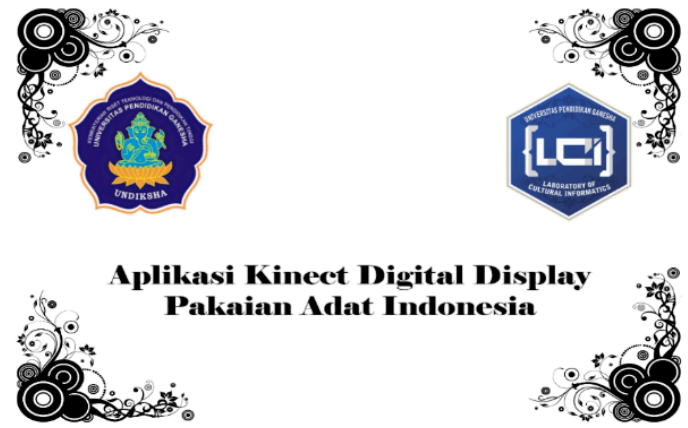

Gambar 9. Implementasi Antarmuka Tampilan Layar Intro/Splash Image

b. Implementasi Antarmuka Tampilan Petunjuk Pose Aplikasi

Tampilan petunjuk pose aplikasi (splash image petunjuk pose) akan muncul setelah layar splash image logo UNDIKSHA dan LCI ditampilkan. Fungsi dari tampilan layar petunjuk pose ini adalah memberi gambaran posisi dan gerakan tubuh yang harus dilakukan pengguna di depan kamera kinect ketika aplikasi telah dijalankan. Adapun antarmuka dari tampilan petunjuk aplikasi dapat dilihat pada Gambar 10.
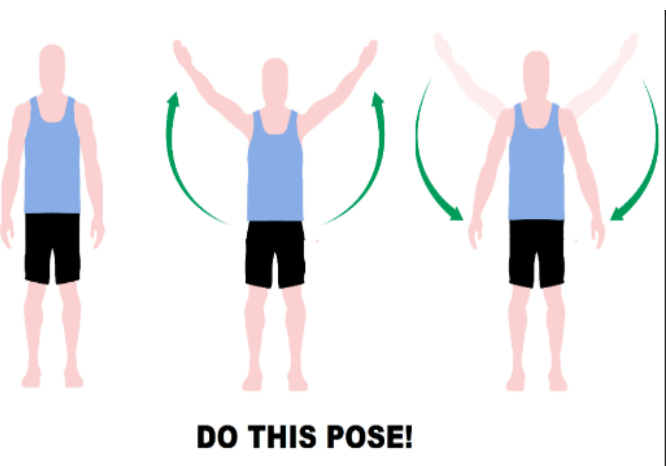

Gambar 10. Implementasi Antarmuka Tampilan Layar Petunjuk Pose Aplikasi c. Implementasi Antarmuka Tampilan Layar Utama Tampilan layar utama muncul setelah splash image nama aplikasi dan splash image petunjuk pose ditampilkan. Pada tampilan layar utama aplikasi akan menampilkan ojek 3D dari pakaian adat wanita dari provinsi Nangroe Aceh Darussalam sebagai objek 3D default aplikasi. Layar utama ini memuat 8 buah tombol diantaranya tombol untuk previous objek, untuk next objek. Tombol previous dan next berfungsi untuk memilih pakaian adat yang ingin ditampilkan. Tombol wanita dan pria untuk menampilkan jenis pakaian dengan gender wanita atau gender pria. Tombol capture untuk men-screenshot tampilan layar utama, serta tombol Indonesia dan tombol Inggris untuk memutar bahasa dari narasi.

Tombol zoom dari aplikasi apabila ditekan akan memunculkan 6 buah sub tombol zoom yang diantaranya berfungsi untuk untuk mengatur ukuran objek 3D dan posisi objek 3D. Tampilan layar utama aplikasi Kinect Digital Display Pakaian Adat Indonesia dapat dilihat pada Gambar 11.a. dan Gambar 11.b untuk tampilan sub tombol zoom aplikasi.

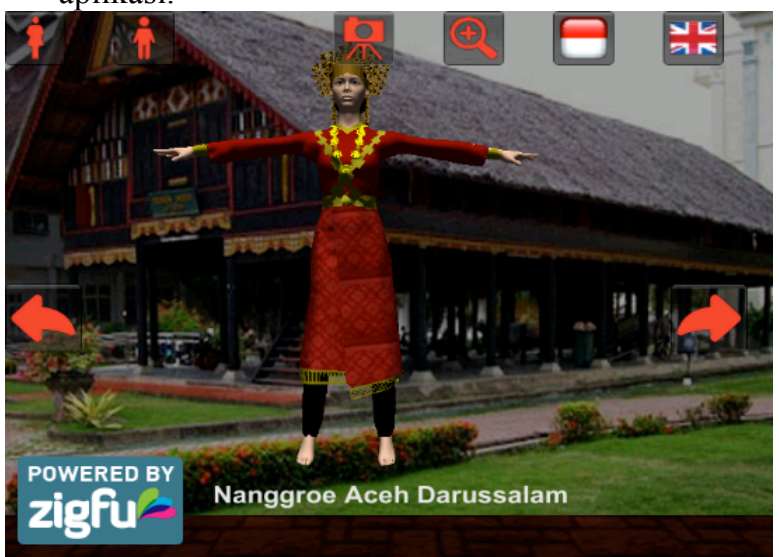

Gambar 11.a Layar Utama

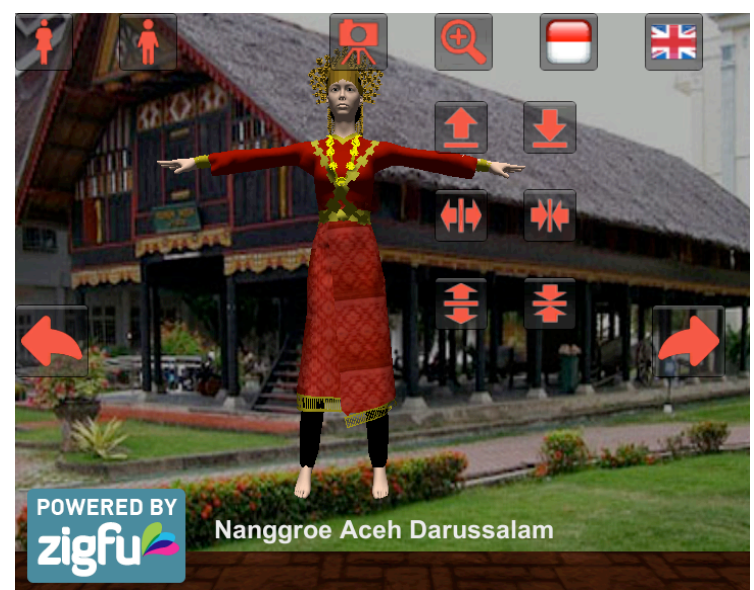

Gambar 11.b Layar Utama (sub tombol zoom) 
p-ISSN 2089-8673 | e-ISSN 2548-4265

Jurnal Nasional Pendidikan Teknik Informatika (JANAPATI)

Volume 6, Nomor 1, Maret 2017

d. Implementasi Objek 3 Dimensi

Pada tahap implementasi objek 3D, pembuatan objek 3D pakaian adat Indonesia ke- 34 provinsi di Indonesia dibuat dengan menggunakan aplikasi Blender 2.76. Jumlah total dari pakaian adat yang dibuat adalah sejumlah 64 objek 3D, yaitu 34 objek 3D pakaian adat wanita dan 34 objek 3D pakaian adat pria. Bentuk dari objek 3D disesuaikan semirip mungkin dengan bentuk asli pakaian adat dari masing-masing daerah. Pada tampilan layar utama aplikasi Kinect Digital Display Pakaian Adat Indonesia akan menampilkan objek 3D pakaian adat Indonesia dengan background berupa gambar rumah adat dari masing - masing daerah sesuai dengan daerah yang dipilih.

Adapun beberapa implementasi objek 3D pakaian adat Indonesia dapat dilihat pada Tabel 3.

Tabel 3. Implementasi Objek 3D Pakaian Adat Indonesia
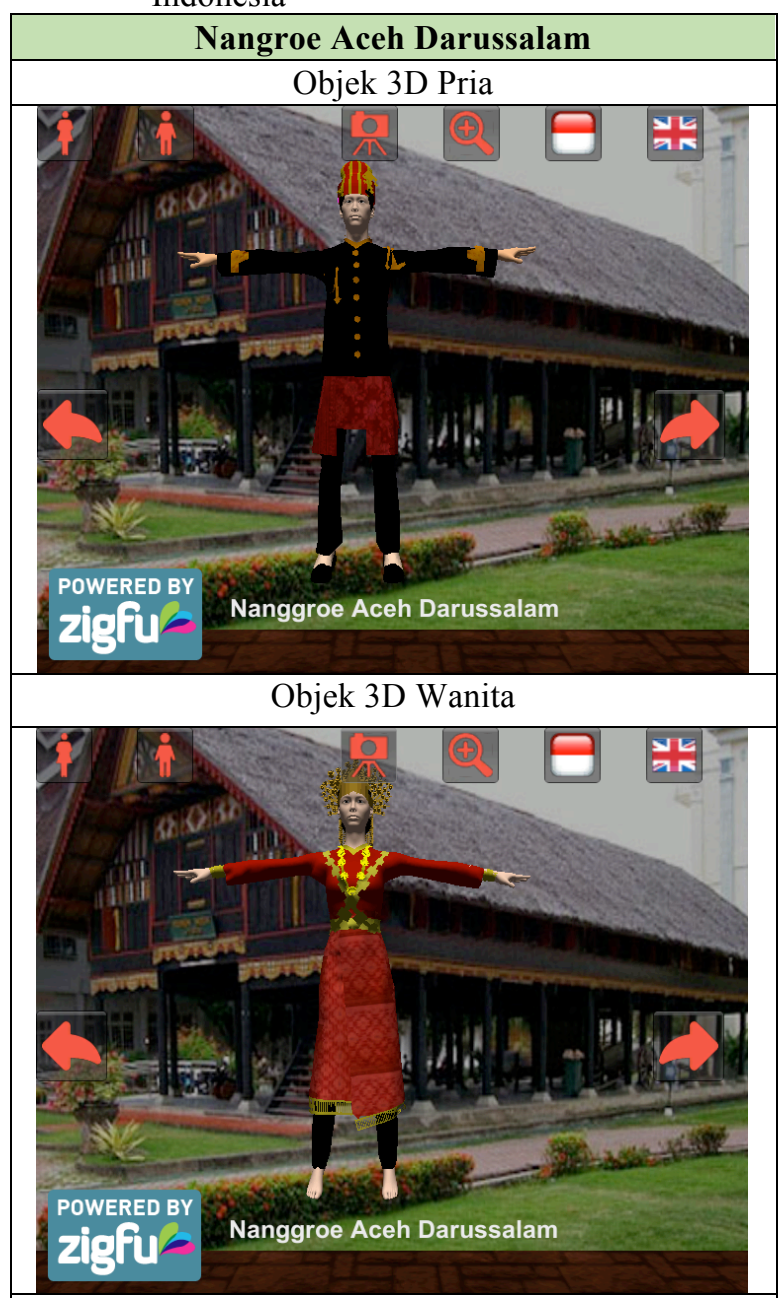
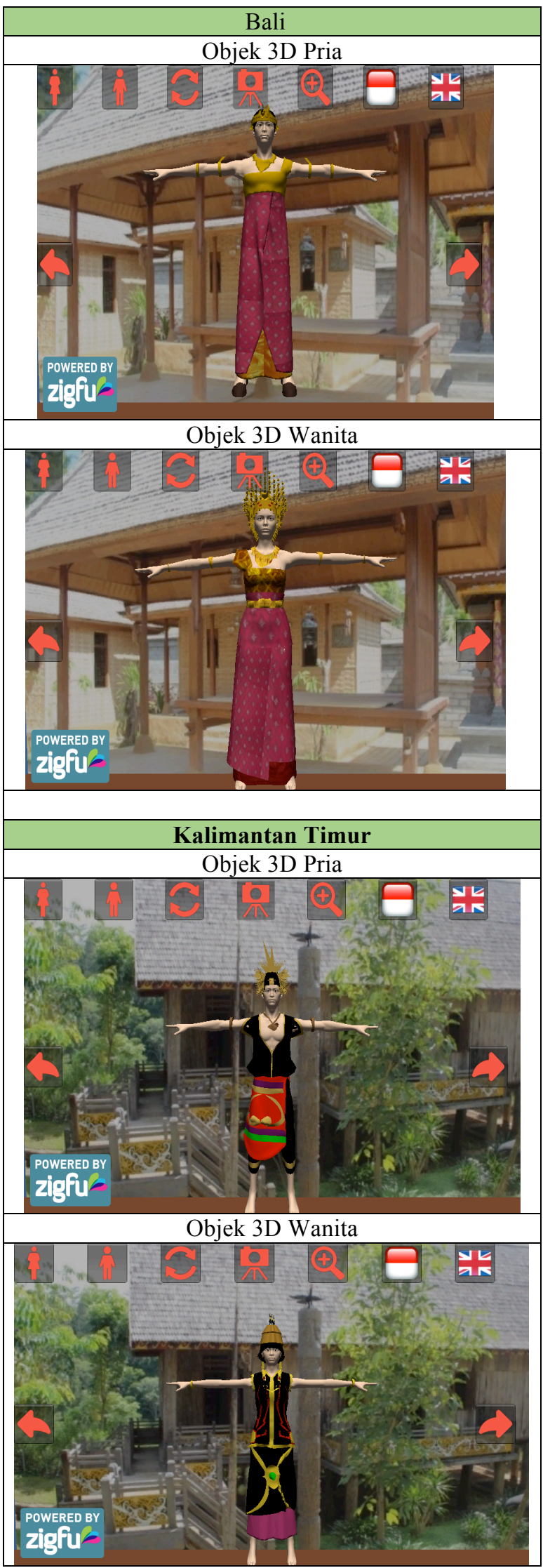


\section{SIMPULAN}

Aplikasi Kinect Digital Display Pakaian Adat Indonesia dirancang untuk memberikan informasi masyarakat tentang pakaian adat tradisional Indonesia yang dirancang menggunakan Use Case Diagram dan Activity Diagram dengan entitas pengguna (user), serta diimplementasikan dengan menggunakan editor UNITY $3 D$ dan plug-in Zigfu yang menghubungkan Kinect dengan UNITY $3 D$ sehingga aplikasi dapat menampilkan objek 3D pakaian adat tradisional Indonesia yang mampu bergerak sesuai dengan gerakan penggunanya. Aplikasi ini hanya menampilkan informasi dalam bentuk visual berupa model 3D dari Pakaian Adat Indonesia dan audio berupa suara mengenai Pakaian Adat Indonesia dalam bahasa Indonesia dan Inggris. Selain itu aplikasi juga dapat mendokumentasikan tampilan layar aplikasi Pakaian Adat Indonesia. Data informasi terkait obyek yang digunakan bersifat statis, dimana data secara langsung disimpan kedalam aplikasi tanpa menggunakan database. Pengembangan aplikasi ini difokuskan dapat berjalan pada sistem operasi Windows. Aplikasi ini telah berhasil diimplementasikan dengan baik dengan spesifikasi perangkat minimal yaitu Spesifikasi perangkat minimal yang diperlukan untuk menjalankan aplikasi yaitu Processor Intel Dualcore, RAM 1 GB, OS Windows XP SP 2, GPU Intel HD. Berdasarkan respon ahli media menyatakan layak untuk dipublikasikan dengan persentase $92,667 \%$, dan 10 respon pengguna yang sangat positif terhadap Aplikasi Kinect Digital Display Pakaian Adat Indonesia ini dengan persentase $93,8 \%$. Serta berdasarkan uji kesesuaian proses Aplikasi Kinect Digital Display Pakaian Adat Indonesia hanya dapat berjalan dengan baik pada perangkat dengan spesifikasi 32 bit.

Berdasarkan hasil penelitian pengembangan dan kesimpulan, dapat disarankan bagi pembaca yang ingin mengembangkan sistem ini diantaranya: 1). Objek busana yang ada dalam aplikasi ini memiliki kapasitas yang besar dan berat, jadi untuk pengembangan selanjutnya agar diusahakan untuk membuat objek $3 D$ yang lebih ringan tetapi tetap detail. 2). Untuk pengembangan aplikasi selanjutnya, agar dapat memanfaatkan teknologi kinect dengan lebih baik. Diharapkan aplikasi dapat dikembangkan dengan motion gestur untuk memilih tombol. 3). Untuk pengembangan aplikasi selanjutnya, diharapkan mencari lebih banyak refrensi dan kajian mengenai penggunaan kinect. 4). Untuk pengembangan aplikasi selanjutnya, agar memperhitungkan faktor jarak, posisi dan cahaya untuk mengoptimalkan fungsi dari kinect.

\section{REFERENSI}

[1] Kementrian Dalam Negeri. 2013. "Pembentukan DaerahDaerah Otonom Di Indonesia Sampai Dengan Tahun 2013"

http://otda.kemendagri.go.id/images/file/data_dob/total\% 20daerah\%20otonom\%202013.pdf (diakses pada tanggal 7 Januari 2015).

[2] Museum Bali. 2014. Buku Panduan Museum Bali. Denpasar : UPT. Museum Bali

[4] Cahyawardhani. 2012. Museum di Indonesia: Apa Kabarnya? Tersedia pada http://intisarionline.com/read/museum-di-indonesia-apa-kabarnya. (Diakses tanggal 11 Januari 2015)

[5] Panji, Aditya. 2012. " 'Augmented Reality' Bantuan Pelajari Budaya Indonesia”. http://tekno.kompas.com/read/2012/11/30/09140683/quot augmented.realityquot.bantu.pelajari.budaya.indonesia (Diakses tanggal 19 Februari 2015).

[5] Ahira, Anne. 2013. "Pakaian Adat Indonesia". http://www.anneahira.com/pakaian -adat-indonesia.htm (diakses pada tanggal 2 Januari 2015).

[6] Low, Adrian (1991). Introduction Computer Vision and Image Processing. McGraw- Hill Book, Company, UK

[7] Fernandez, Adso. Dkk. 2012. "Biomechanical Validation of Upper-body and Lower-body Joint Movements of Kinect Motion Capture Data". http://upcommons.upc.edu/eprints/bitstream/2117/17117/1/incos2012_656_6 61.pdf. (diakses pada tanggal 9 Maret 2016).

[8] Sihite, B. 2013. Pembuatan Aplikasi 3D Viewer Mobile dengan Menggunakan Teknologi Virtual Reality. Jurnal Teknik Pomits 2(2) A397-A400. 